\title{
Plasma-Assisted Synthesis of Multicomponent Nanoparticles Containing Carbon, Tungsten Carbide and Silver as Multifunctional Filler for Polylactic Acid Composite Films
}

\author{
Nichapat Boonyeun ${ }^{1,2}\left(\mathbb{D}\right.$, Ratana Rujiravanit $1,2, * \mathbb{D}$ and Nagahiro Saito ${ }^{3}$ \\ 1 The Petroleum and Petrochemical College, Chulalongkorn University, Bangkok 10330, Thailand; \\ Nichapat.B@student.chula.ac.th \\ 2 Center of Excellence on Petrochemical and Materials Technology, Chulalongkorn University, \\ Bangkok 10330, Thailand \\ 3 Department of Chemical Systems Engineering, Graduate School of Engineering, Nagoya University, \\ Nagoya 464-8603, Japan; Hiro@sp.material.nagoya-u.ac.jp \\ * Correspondence: Ratana.r@chula.ac.th; Tel.: +662-218-4132
}

check for updates

Citation: Boonyeun, N.; Rujiravanit, R.; Saito, N. Plasma-Assisted Synthesis of Multicomponent Nanoparticles Containing Carbon, Tungsten Carbide and Silver as Multifunctional Filler for Polylactic Acid Composite Films. Polymers 2021, 13, 991. https://doi.org/10.3390/ polym13070991

Academic Editor: Choon-Sang Park

Received: 26 February 2021

Accepted: 20 March 2021

Published: 24 March 2021

Publisher's Note: MDPI stays neutral with regard to jurisdictional claims in published maps and institutional affiliations.

Copyright: (c) 2021 by the authors. Licensee MDPI, Basel, Switzerland. This article is an open access article distributed under the terms and conditions of the Creative Commons Attribution (CC BY) license (https:/ / creativecommons.org/licenses/by/ $4.0 /)$.

\begin{abstract}
Multicomponent nanoparticles containing carbon, tungsten carbide and silver (carbon-WCAg nanoparticles) were simply synthesized via in-liquid electrical discharge plasma, the so-called solution plasma process, by using tungsten electrodes immersed in palm oil containing droplets of $\mathrm{AgNO}_{3}$ solution as carbon and silver precursors, respectively. The atomic ratio of carbon:W:Ag in carbon-WC-Ag nanoparticles was 20:1:3. FE-SEM images revealed that the synthesized carbon-WCAg nanoparticles with particle sizes in the range of $20-400 \mathrm{~nm}$ had a spherical shape with a bumpy surface. TEM images of carbon-WC-Ag nanoparticles showed that tungsten carbide nanoparticles (WCNPs) and silver nanoparticles (AgNPs) with average particle sizes of $3.46 \mathrm{~nm}$ and $72.74 \mathrm{~nm}$, respectively, were dispersed in amorphous carbon. The carbon-WC-Ag nanoparticles were used as multifunctional fillers for the preparation of polylactic acid (PLA) composite films, i.e., PLA/carbonWC-Ag, by solution casting. Interestingly, the coexistence of WCNPs and AgNPs in carbon-WC-Ag nanoparticles provided a benefit for the co-nucleation ability of WCNPs and AgNPs, resulting in enhanced crystallization of PLA, as evidenced by the reduction in the cold crystallization temperature of PLA. At the low content of $1.23 \mathrm{wt} \%$ carbon-WC-Ag nanoparticles, the Young's modulus and tensile strength of PLA/carbon-WC-Ag composite films were increased to $25.12 \%$ and $46.08 \%$, respectively. Moreover, the PLA/carbon-WC-Ag composite films possessed antibacterial activities.
\end{abstract}

Keywords: atmospheric pressure plasma; filler; polylactic acid; polymer composite

\section{Introduction}

Nowadays, due to increasing environmental concerns and climate change worldwide, bio-derived and biodegradable polymers such as polylactic acid (PLA), polyhydroxybutyrate (PHB) and poly(3-hydroxybutyrate-co-3-hydroxyvalerate) (PHBV) have received much attention as alternatives to petroleum-based polymers [1-3]. Among bio-derived and biodegradable polymers, PLA is one of the most studied polymers and has been investigated for many applications, such as packaging materials [4], membranes for separation processes [5] and biomaterials for biomedical applications [6]. Nevertheless, the major drawbacks of PLA that limit its utilization as a replacement for petroleum-based polymers are low thermal stability, inferior mechanical properties and low crystallization rate when compared with petroleum-based polymers. Therefore, the incorporation of fillers into PLA to obtain PLA composites has been considered as an effective method to overcome these limitations. To date, PLA composites have been developed by the incorporation of a wide variety of fillers, such as clay [7], silver nanoparticles [8], zinc oxide ( $\mathrm{ZnO})$ [9], tungsten disulfide $\left(\mathrm{WS}_{2}\right)$ nanotubes [10] and various types of carbon materials [11-13]. 
Among the investigated fillers, carbon materials have been considered as efficient candidates for the development of PLA composites because of their outstanding properties, such as high surface area, high thermal and chemical stability, high absorption ability and low cost $[14,15]$. However, the incorporation of monocomponent fillers could improve only specific properties of polymers $[16,17]$. Hence, the incorporation of multicomponent fillers into polymers has been employed in order to accomplish simultaneous improvement of the multifunctional properties of polymers, such as mechanical properties, thermal properties, crystallization behavior and antibacterial activities [18,19]. According to previous reports, the aggregation and non-homogeneous dispersion of each component in polymer matrices could occur, resulting in the deterioration of the properties of polymers [20,21]. To overcome these problems, nanohybrid fillers such as cellulose/silver nanoparticles and multiwall carbon nanotubes (MWCNTs)/ silver nanoparticles were fabricated and incorporated into polymers $[8,22,23]$. However, the preparation methods of the nanohybrid fillers commonly involved time-consuming processes and the utilization of chemical agents.

The solution plasma process (SPP), an electrical discharge of plasma occurring in a liquid phase, has been considered as an emerging technology that has been investigated in carbon synthesis [24-26], surface modification of carbon materials [27], synthesis of metal nanoparticles [28,29] and synthesis of carbon-supported metal nanoparticles [30,31]. SPP is operated by applying electric potential between a pair of metal electrodes that are immersed in a liquid phase. Energetic electrons that are released from the electrodes collide with molecules near the electrodes, resulting in the formation of a variety of highly active species, such as excited molecules, free electrons, free radicals and positively and negatively charged species. Moreover, as a result of electron bombardment at the surfaces of electrodes, the erosion of the electrodes may occur, leading to the formation of metal nanoparticles released from the electrodes [30,32]. For example, when tungsten electrodes were used in carbon synthesis by SPP, to some extent, tungsten carbide nanoparticles were generated together with the formation of carbon as a result of the sputtering of tungsten electrodes [33]. Under this circumstance, SPP can provide several benefits, such as accelerating reaction rate, lowering reaction temperature and reduction of chemicals used in various reactions, e.g., synthesis of metal nanoparticles [34,35]. Recently, different types of organic solvents, including benzene, cyclohexane and hexane, have been investigated as carbon precursors to synthesize carbon by using SPP $[24,33,36]$. However, the organic solvents are high-cost raw materials and their wastes from the reactions may cause environmental problems. As an alternative to organic solvents, palm oil, a carbon-rich renewable raw material consisting of triglycerides and fatty acids [37,38], is a potential carbon precursor for synthesis of carbon by SPP. It was postulated that long-chain hydrocarbon moieties in fatty acids that are present in palm oil can be converted to carbon by SPP. The mechanism for the conversion of carbon precursors to carbon materials by SPP was proposed by Morishita T et al., 2016 [36].

In the last decade, inorganic fillers with intrinsic antimicrobial properties, such as titanium dioxide [39,40], zinc oxide [41], graphene oxide (GO) [42], metal-organic frameworks (MOFs) [43] and silver nanoparticles (AgNPs) [44], have been applied to polymer composites in order to introduce antimicrobial functions to the composites. It is known that AgNPs are one of the most powerful antimicrobial agents. Nowadays, AgNPs are extensively utilized in a broad range of applications, such as conductive materials [45], catalysts [46], anticancer [47] and biomaterials [48]. However, the stability of AgNPs is an important issue hindering their application. As their particle sizes are in the nano-scale, the surface energy of AgNPs is high, resulting in a tendency to undergo aggregation [49]. The aggregation of AgNPs results in a reduction in their performance, such as their catalytic efficiency and antimicrobial activities [50,51]. In order to prevent the aggregation of AgNPs, the deposition of AgNPs on various supporting materials, such as silica, zeolite and carbon, has been explored [52,53]. Among the most widely used supporting materials, carbon materials have many advantages, including high surface area, stability in acid and base media and low cost. Therefore, carbon materials are considered as potential candidates for use as supporting materials for AgNPs to obtain carbon-supported AgNPs [54,55]. Nowa- 
days, carbon-supported AgNPs are extensively used as reinforcing fillers for polymer composites [22,56,57]. According to the literature, carbon-supported AgNPs can be synthesized by several methods, such as hydrothermal reduction [58], thermal annealing [56] and sputtering deposition [59]. However, the preparation of carbon-supported AgNPs is generally based on multi-step processes together with the use of reducing agents and long reaction times.

In this study, multicomponent nanoparticles containing carbon, tungsten carbide and silver, i.e., carbon-WC-Ag nanoparticles, were synthesized in one step via SPP by using palm oil containing droplets of silver nitrate $\left(\mathrm{AgNO}_{3}\right)$ solution as carbon and silver precursors, respectively. By applying SPP, carbon and AgNPs were synthesized from palm oil and $\mathrm{AgNO}_{3}$, respectively, whereas tungsten carbide nanoparticles (WCNPs) were generated by the sputtering of tungsten electrodes together with the simultaneous formation of carbon during plasma discharge. The morphology and elemental composition of carbon-WC-Ag nanoparticles were characterized. Carbon-WC-Ag nanoparticles were then used as multifunctional fillers for the preparation of polylactic acid (PLA) composite films, i.e., PLA/carbon-WC-Ag, by solution casting. The effect of carbon-WC-Ag nanoparticles on the non-isothermal crystallization behavior and mechanical and thermal properties of the obtained PLA composite films was investigated. The antibacterial activities of PLA/carbon-WC-Ag composite films against Escherichia coli, a Gram-negative bacterium, and Staphylococcus aureus, a Gram-positive bacterium, were also examined.

\section{Materials and Methods}

\subsection{Materials}

Polylactic acid (PLA) (Ingeo ${ }^{\mathrm{TM}}$ 4043D) with 94\% L-lactide and 6\% D-lactide was provided by Natureworks LLC (Minnetonka, MN, USA) (molecular weight $\left(\mathrm{M}_{\mathrm{w}}\right)$ of $1.5 \times 10^{5} \mathrm{~g} / \mathrm{mol}$ and polydispersity index (PDI) of 1.81). The melt flow index and density of PLA are $6.0 \mathrm{~g} / 10 \mathrm{~min}$ and $1.24 \mathrm{~g} / \mathrm{cm}^{3}$, respectively. Activated charcoal was purchased from Sigma-Aldrich Inc. (Lyon, France). Silver nitrate $\left(\mathrm{AgNO}_{3}\right)$ was supplied by Fisher Scientific Co., Ltd. (Loughboroug, UK). Tungsten (W) and silver (Ag) electrodes (diameter of $1 \mathrm{~mm}, 99.95 \%$ purity) were obtained from The Nilaco Corporation, Japan. Chloroform $\left(\mathrm{CHCl}_{3}\right)$ and hexane $\left(\mathrm{C}_{6} \mathrm{H}_{8}\right)$ were analytical-grade and bought from RCI Labscan Co., Ltd. (Bangkok, Thailand). Palm oil was provided by Oleen Co., Ltd. (Samutsakhon, Thailand). Escherichia coli strain TISTR 527 and Stapphylococcus aureus strain TISTR 2329 were supplied by the Microbiological Resource Center, Thailand Institute of Scientific and Technological Research (TISTR). Bacteriological-grade beef extract, peptone and agar powder were purchased from HiMedia Laboratory Co., Ltd. (Maharashtra, India).

\subsection{Preparation of Carbon-WC, Carbon-Ag and Carbon-WC-Ag Nanoparticles via SPP}

The experimental setup of SPP is shown in Figure 1a. The plasma discharge was carried out at room temperature and atmospheric pressure by using a bipolar pulsed power supply (model Pekuris MPS-06K01C-WP1 from Kurita Seisakusho Co., Ltd., Kyoto, Japan). The plasma discharge was generated between a pair of metal electrodes equipped in a glass reactor that was filled with palm oil $(40 \mathrm{~mL})$. Two types of metal electrodes, i.e., tungsten (W) and silver (Ag) electrodes, were used to synthesize carbon-WC and carbon-Ag nanoparticles, respectively. The metal electrodes were insulated by ceramic tubes. The gap between the electrodes, voltage, pulse frequency, pulse width and plasma discharge time were $0.5 \mathrm{~mm}, 1.64 \mathrm{kV}, 15 \mathrm{kHz}, 2$ s and $90 \mathrm{~min}$, respectively. Palm oil was used as a carbon precursor to synthesize carbon via SPP, whereas tungsten carbide nanoparticles (WCNPs) were generated by sputtering of tungsten electrodes and subsequently combining tungsten and carbon. For the synthesis of carbon-WC-Ag nanoparticles, $\mathrm{AgNO}_{3}$ solution $(10 \mathrm{~mL})$ at a concentration of $0.02 \mathrm{M}$ was added into palm oil $(40 \mathrm{~mL})$ under strong agitation to form small droplets of $\mathrm{AgNO}_{3}$ solution that dispersed in palm oil while plasma discharge was taking place. The operating conditions for plasma discharge were the same as those for the synthesis of carbon-WC and carbon-Ag nanoparticles. 


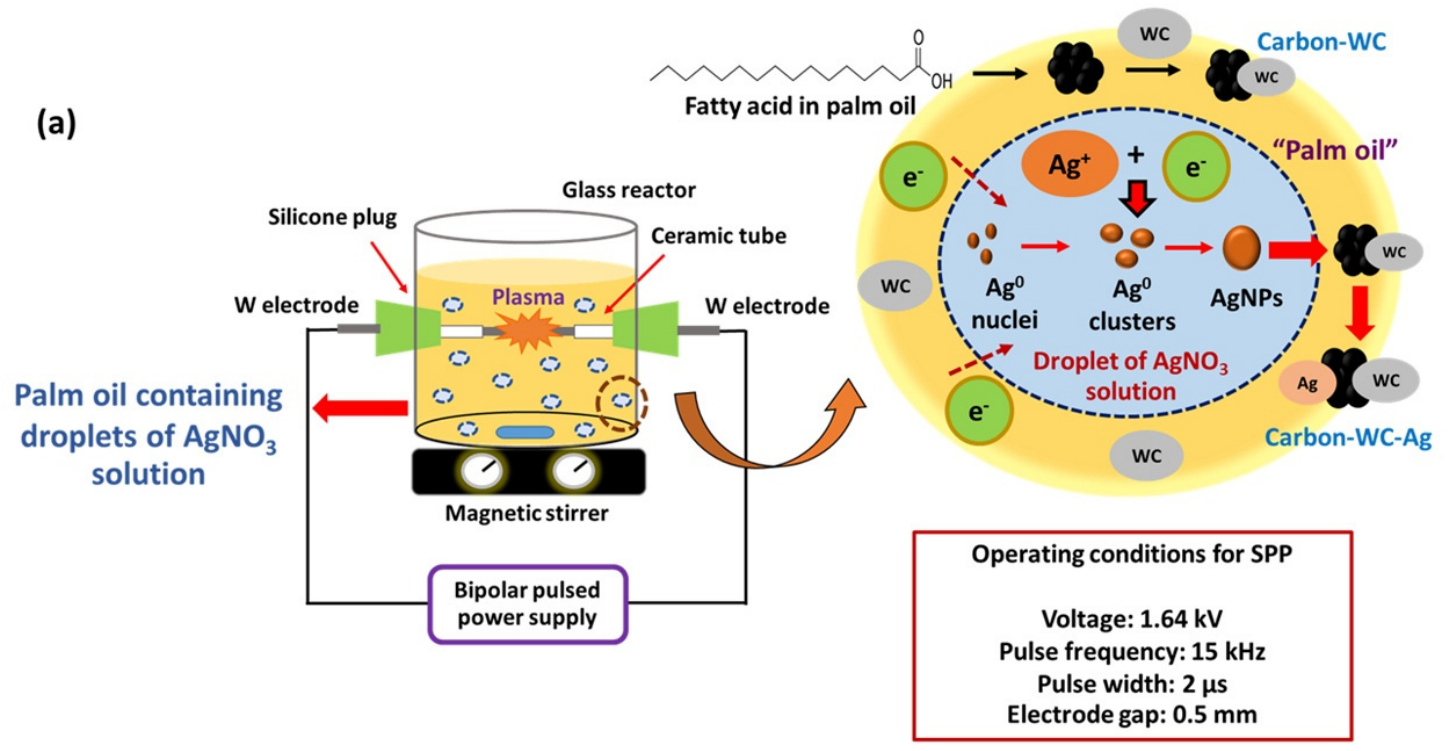

(b)
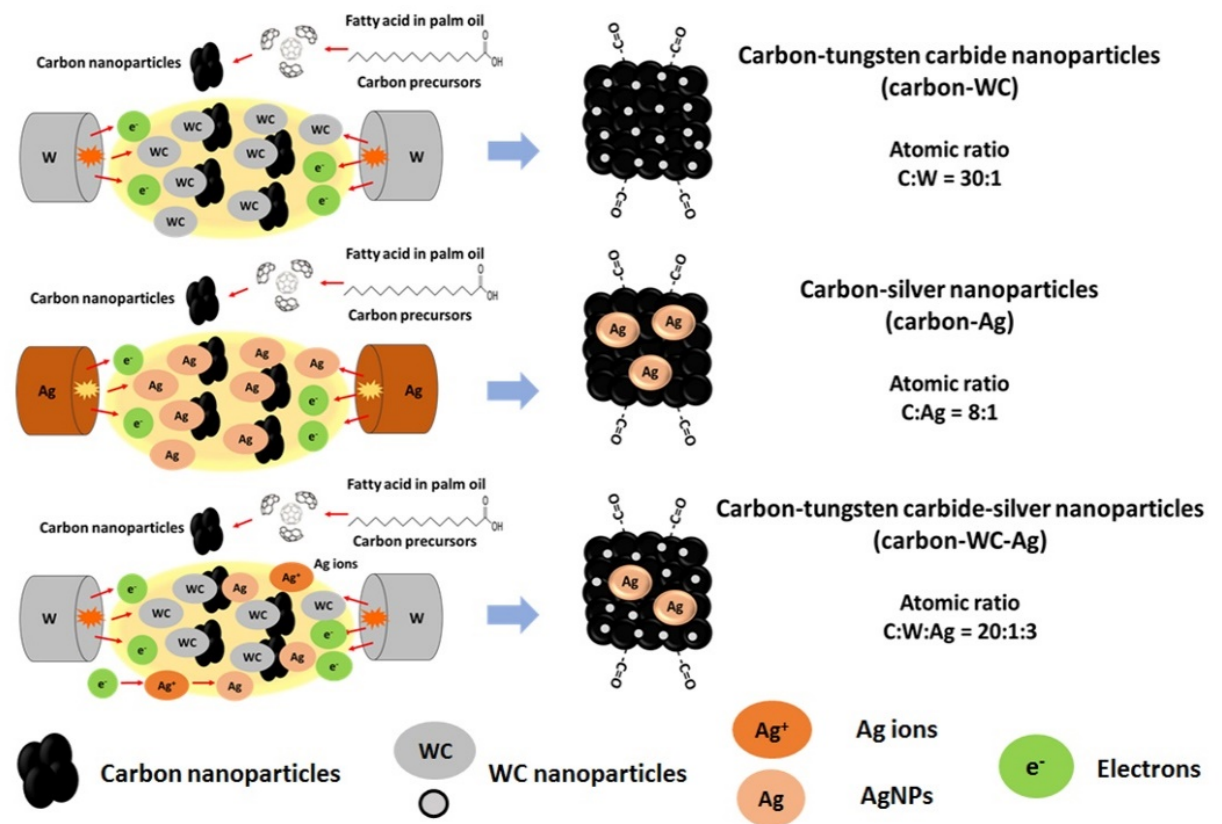

Figure 1. (a) Schematic diagrams of SPP and formation of AgNPs in a droplet of $\mathrm{AgNO}_{3}$ solution dispersed in palm oil, and (b) formation of carbon-based nanoparticles, i.e., carbon-WC, carbon-Ag and carbon-WC-Ag nanoparticles, synthesized by SPP using tungsten (W) and silver (Ag) electrodes.

By applying SPP and using tungsten electrodes, palm oil and $\mathrm{AgNO}_{3}$ solution acted as carbon and Ag precursors to synthesize carbon-WC-Ag nanoparticles in one step. Based on the types of electrodes, i.e., tungsten and silver electrodes, there were three types of synthesized carbon-based nanoparticles, i.e., carbon-tungsten carbide (carbon-WC), carbonsilver (carbon-Ag) and carbon-tungsten carbide-silver (carbon-WC-Ag) nanoparticles, as illustrated in Figure 1b. After the plasma discharge, the synthesized carbon-based nanoparticles were collected and separated from palm oil by centrifugation at a rotational speed of 12,000 rpm for $15 \mathrm{~min}$. Then, the synthesized carbon-based nanoparticles were rinsed with an excess amount of hexane to remove the residual oil, followed by centrifugation at a rotational speed of 12,000 rpm for $15 \mathrm{~min}$. The washing process was repeated 3 times. The synthesized carbon-based nanoparticles were dried in an oven at $60{ }^{\circ} \mathrm{C}$ for $3 \mathrm{~h}$. 


\subsection{Preparation of Neat PLA and PLA Composite Films}

For preparation of neat PLA films, a PLA solution at a concentration of $4 \%(w / v)$ was prepared by dissolving PLA pellets of $4 \mathrm{~g}$ in chloroform $100 \mathrm{~mL}$, followed by stirring at $60{ }^{\circ} \mathrm{C}$ for $2 \mathrm{~h}$ until PLA pellets were completely dissolved [60]. Then, the PLA solution was cast on Petri dishes and left at room temperature for $48 \mathrm{~h}$ to obtain neat PLA films. For preparation of PLA composite films, the fillers, i.e., activated charcoal, carbon-WC, carbon$\mathrm{Ag}$ and carbon-WC-Ag nanoparticles, were dispersed in the PLA solutions, followed by sonication for $10 \mathrm{~min}$. The filler contents in the PLA composite films were varied to be $0.25,0.75,1.23,1.72$ and $2.20 \mathrm{wt} \%$, as shown in Table 1. After this, the PLA solutions containing each type of filler were cast on Petri dishes and left at room temperature for $48 \mathrm{~h}$ to evaporate the solvent, and PLA composite films having a thickness of $95.5 \mu \mathrm{m}$ were obtained.

Table 1. The amounts of fillers, PLA and chloroform for the preparation of PLA composite films.

\begin{tabular}{cccc}
\hline Fillers $(\mathbf{g})$ & PLA $(\mathbf{g})$ & Chloroform $(\mathbf{m L})$ & Filler Content in PLA Composite Films (wt $\%)$ \\
\hline 0.01 & 4.00 & 100.00 & 0.25 \\
0.03 & 4.00 & 100.00 & 0.75 \\
0.05 & 4.00 & 100.00 & 1.23 \\
0.07 & 4.00 & 100.00 & 1.72 \\
0.09 & 4.00 & 100.00 & 2.20 \\
\hline
\end{tabular}

\subsection{Characterization}

The synthesized carbon-based nanoparticles were characterized in comparison with the commercial activated charcoal. Wide angle X-ray diffraction (WAXD) measurements were done by using SmartLab (Rigaku Corporation, Tokyo, Japan) with $\mathrm{CuK} \alpha$ radiation $(\lambda=0.154 \mathrm{~nm})$ operating at $40 \mathrm{kV}$ and $30 \mathrm{~mA}$. The values of degree of crystallinity $\left(\chi_{c}\right)$ of neat PLA and the PLA composite films were determined according to Equation (1):

$$
\chi_{\mathrm{c}}(\%)=\left[\left(A_{c} /\left(A_{c}+A_{a}\right)\right] \times 100 \%\right.
$$

$A_{c}$ represents the area under the total crystalline region and $A_{a}$ represents the area under the total amorphous region [61].

Chemical compositions of activated charcoal and the synthesized carbon-based nanoparticles were analyzed by XPS (model Kratos Axis Ultra DLD from Kratos Analytical Co., Ltd., Manchester, UK) with an Al K $\alpha$ X-ray source at $15 \mathrm{kV}$. Raman spectra of the synthesized carbon-based nanoparticles were detected by Spectra GX (Perkin Elmer Inc., Waltham, MA, USA). TEM and FE-SEM images of the synthesized carbon-based nanoparticles were taken using a JEOL (model JEM-2100 from JEOL Co., Ltd., Tokyo, Japan) and Hitachi (model s-4800 from Hitachi Co., Ltd., Tokyo, Japan), respectively. The elemental compositions of activated charcoal and the synthesized carbon-based nanoparticles were determined by scanning electron microscopy with energy dispersive X-ray (SEM-EDX) (Hitach Co., Ltd., Tokyo, Japan).

Surface and cross-sectional morphology of neat PLA and PLA composite films was observed by FE-SEM (Hitachi s-4800, Japan). All samples were coated with platinum before measurements. The thermal properties of neat PLA and PLA composite films were investigated using TGA (model Netzsch 209F3 from Netzsch Co., Ltd., Selb, Germany) under a nitrogen atmosphere. All samples were heated from $35^{\circ} \mathrm{C}$ to $900{ }^{\circ} \mathrm{C}$ at a heating rate of $10{ }^{\circ} \mathrm{C} / \mathrm{min}$. The crystallization behavior of neat PLA and PLA composite films was investigated by differential scanning calorimetry (DSC) (model Netzsch 204F1 Phoenix from Netzsch Co., Ltd., Selb, Germany) under a nitrogen atmosphere. For all samples, the first heating scan was performed by heating the samples to $200{ }^{\circ} \mathrm{C}$ at a heating rate of $10^{\circ} \mathrm{C} / \mathrm{min}$ to eliminate thermal histories. After this, the samples were cooled down to $25^{\circ} \mathrm{C}$ at a cooling rate of $10{ }^{\circ} \mathrm{C} / \mathrm{min}$. The second heating scan was performed by heating the samples to $200{ }^{\circ} \mathrm{C}$ at a heating rate of $10^{\circ} \mathrm{C} / \mathrm{min}$. The glass transition temperature $\left(\mathrm{T}_{\mathrm{g}}\right)$, the 
cold crystallization temperature $\left(\mathrm{T}_{\mathrm{cc}}\right)$ and the melting temperature $\left(\mathrm{T}_{\mathrm{m}}\right)$ were determined from the second heating scan. Alumina crucible pans (Netzsch Co., Ltd., Selb, Germany) were used for TGA and DSC measurements. Young's modulus and tensile strength of neat PLA and PLA composite films were measured by using a universal testing machine (model Lloyd LRX from Lloyd Instruments Co., Ltd., West Sussex, UK) according to the ASTM D882 with a 500-N load cell. Each datum was the average of 5 specimens. Antibacterial activities of neat PLA, PLA/activated charcoal, PLA/carbon-WC and PLA/carbon-WC-Ag composite films against Escherichia coli (E. coli) and Staphylococcus aureus (S. aureus) were investigated by using the colony-forming unit assay according to the modified procedure of Janpetch et al. 2016 [62]. The bacterial reduction rate (BRR) was calculated according to Equation (2):

$$
\text { Bacterial reduction rate }=\left[\left(N_{1}-N_{2}\right) / N_{1}\right] \times 100 \%
$$

where $N_{1}$ represents the number of colonies from the blank cell suspension and $N_{2}$ represents the number of colonies from the cell suspension containing PLA samples.

\subsection{Statistical Analysis}

The significant differences in the selected parameters were evaluated via analysis of variance (ANOVA) according to Turkey's HSD (honestly significant difference) test at $p$-value $<0.05$ using IBM SPSS Statistics 26 software (SPSS Inc., Chicago, IL, USA).

\section{Results and Discussion}

\subsection{Characterization of Carbon-WC and Carbon-WC-Ag Nanoparticles}

According to the previous studies on SPP, active species such as $\mathrm{H}, \mathrm{C}_{2}$ and $\mathrm{W}$ radicals were generated during plasma discharge in organic solvents by using tungsten electrodes due to the dissociation of the molecules of organic solvents and the sputtering of tungsten electrodes $[26,33]$. The formation of carbon mainly depended on the interactions of the generated $C_{2}$ radicals with each other, resulting in the formation of polycyclic structures. In this study, the pathways of carbon formation from palm oil by SPP were postulated to involve the transformation of hydrocarbon moieties of fatty acids existing in palm oil to cyclic compounds. Subsequently, the cyclic compounds underwent recombination to form polycyclic structures and eventually converted to a network structure of carbon, as described in previous studies $[33,36]$.

In addition, tungsten carbide (WC) could be formed during plasma discharge by the reaction between $W$ and $C_{2}$ radicals and subsequently embedded in the simultaneously generated carbon, resulting in the formation of carbon containing tungsten carbide (carbonWC). Figure 2a displays the XRD pattern of carbon-WC in comparison with that of activated charcoal. The characteristic peaks of activated charcoal at $2 \theta=23^{\circ}$ and $43^{\circ}$ corresponding to the reflections of the (002) and (100) planes, respectively, indicated an amorphous state of activated charcoal. From the XRD pattern of carbon-WC, a very broad peak at $2 \theta=25^{\circ}$ suggested the amorphous state of carbon-WC. However, the peaks at $2 \theta=36.7^{\circ}, 42.6^{\circ}$, $61.8^{\circ}, 74.1^{\circ}$ and $78.0^{\circ}$, corresponding to the (111), (200), (220), (311) and (222) planes of metastable tungsten carbide $\left(\mathrm{WC}_{1-\mathrm{x}}\right)$, were also observed in the XRD pattern of carbonWC $[33,63]$. Furthermore, a peak at $2 \theta=38.5^{\circ}$ corresponding to the $(110)$ plane of tungsten metal appeared at a very low intensity. This might be explained by the fact that tungsten metal originated from the erosion of tungsten electrodes during plasma discharge [33,64]. The amount of tungsten metal incorporated into carbon-WC was relatively low due to the very low intensity of the peak of tungsten metal. Accordingly, carbon-WC synthesized by SPP in this study was referred to as the synthesized carbon that contained metastable tungsten carbide and a negligible amount of tungsten metal. 

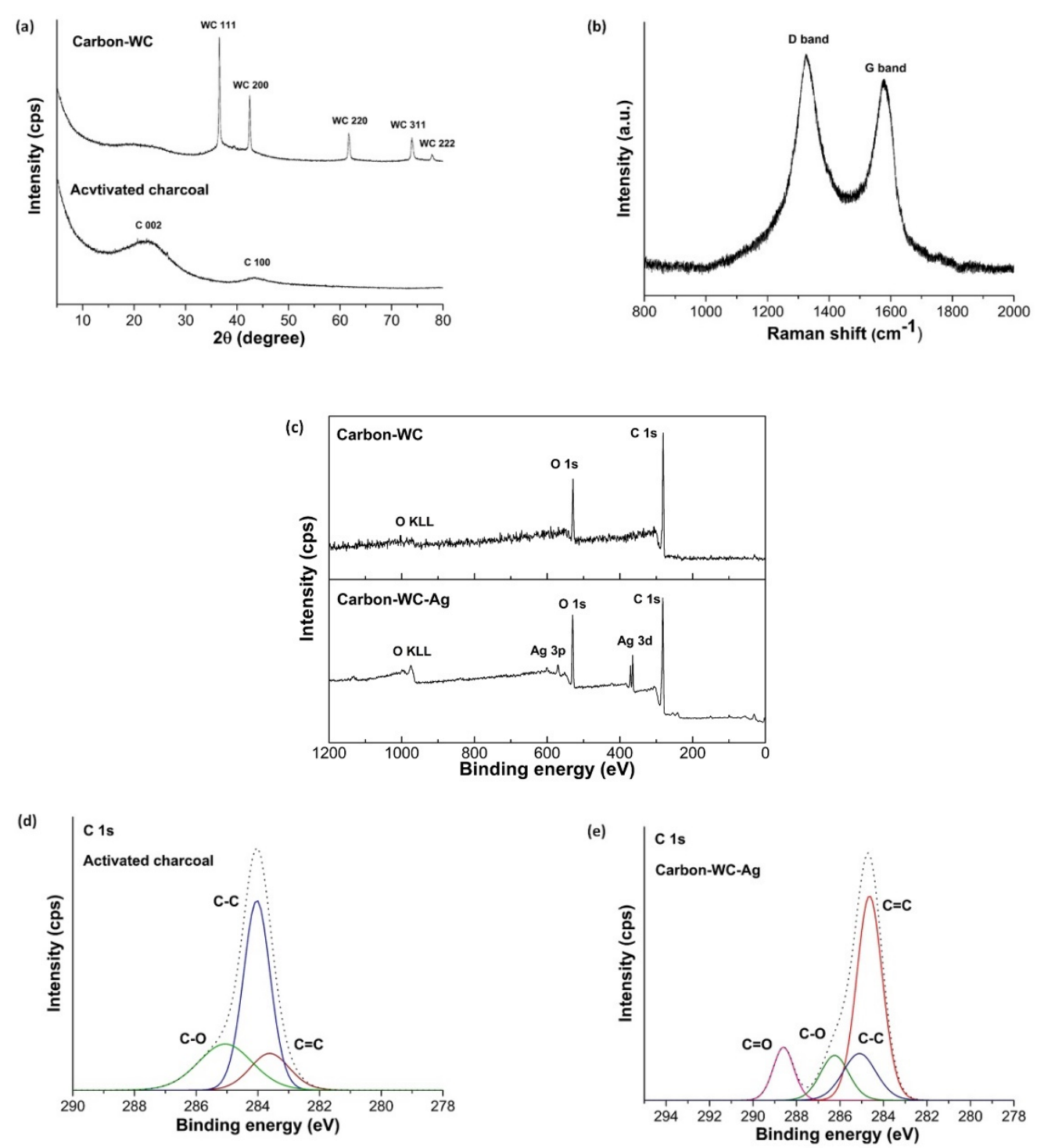

Figure 2. (a) XRD patterns of carbon-WC and activated charcoal, (b) Raman spectrum of carbon-WC, (c) wide-scan XPS spectra of carbon-WC and carbon-WC-Ag nanoparticles, and (d) narrow-scan XPS spectra of C 1s of activated charcoal and (e) carbon-WC-Ag nanoparticles.

In Figure 2b, the Raman spectrum of carbon-WC consists of two peaks at $1350 \mathrm{~cm}^{-1}$ and $1580 \mathrm{~cm}^{-1}$ which correspond to the D band and G band, respectively. The D band is attributed to the occurrence of defects and disorder in the graphitic structure, whereas the $\mathrm{G}$ band is attributed to the formation of a well-organized graphitic structure. According to the obtained Raman spectrum, the intensity of the D band was slightly higher than the intensity of the $\mathrm{G}$ band, indicating an amorphous state of carbon-WC.

The wide-scan XPS spectra of carbon-WC and carbon-WC-Ag nanoparticles are shown in Figure 2c. The peaks of carbon $\mathrm{C} 1 \mathrm{~s}$ and oxygen $\mathrm{O} 1 \mathrm{~s}$ were detected for carbon-WC and carbon-WC-Ag nanoparticles, whereas the wide-scan XPS spectrum of carbon-WC$\mathrm{Ag}$ nanoparticles shows the characteristic peaks of $\mathrm{Ag} 3 \mathrm{~d}$ at $368.05 \mathrm{eV}$ and $374.1 \mathrm{eV}$ and the characteristic peaks of Ag 3p at $572.98 \mathrm{eV}$ and $604.3 \mathrm{eV}$ [20]. The narrow-scan XPS spectra of activated charcoal and carbon-WC-Ag nanoparticles are shown in Figure 2d,e, respectively. For activated charcoal, the $\mathrm{C} 1 \mathrm{~s}$ spectra consisted of three peaks located at $283.70 \mathrm{eV}, 284.00 \mathrm{eV}$ and $285.3 \mathrm{eV}$, which corresponded to C=C, C-C and C-O, respectively. For carbon-WC-Ag nanoparticles, the $\mathrm{C}$ 1s spectra consisted of four peaks located at $284.64 \mathrm{eV}, 285.09 \mathrm{eV}, 286.26 \mathrm{eV}$ and $288.59 \mathrm{eV}$, which corresponded to $\mathrm{C}=\mathrm{C}, \mathrm{C}-\mathrm{C}, \mathrm{C}-\mathrm{O}$ and 
$\mathrm{C}=\mathrm{O}$, respectively. The $\mathrm{C}=\mathrm{O}$ was present in carbon-WC-Ag nanoparticles but was absent in activated charcoal. It was suggested that carbonyl groups could be incorporated into the structure of carbon prepared by SPP $[27,65]$.

FE-SEM images of carbon-WC and carbon-WC-Ag nanoparticles are shown in Figure 3a,b, respectively. It was found that the particle sizes of carbon-WC and carbon-WC-Ag nanoparticles were in the ranges of $10-50 \mathrm{~nm}$ and $20-400 \mathrm{~nm}$, respectively. Additionally, the average particle sizes of carbon-WC and carbon-WC-Ag nanoparticles were $22.60 \mathrm{~nm}$ and $129.06 \mathrm{~nm}$, respectively. The particle size distribution of carbon-WC and carbon-WC-Ag nanoparticles is shown in Figure S1a,b. Interestingly, the FE-SEM image of carbon-WC-Ag nanoparticles (Figure $3 b$ ) shows spherical nanoparticles with bumpy surfaces. The presence of WC nanoparticles (WCNPs) in carbon-WC and carbon-WC-Ag nanoparticles was evidenced by TEM images, as shown in Figure $4 \mathrm{~b}-\mathrm{d}$. It can be seen that WCNPs with particle sizes in the range of 2-5 nm were dispersed in amorphous carbon, whereas the TEM image of activated charcoal (Figure 4a) confirmed the amorphous state of activated charcoal. In Figure 4c,d, TEM images of carbon-WC-Ag nanoparticles show that AgNPs having particle sizes in the range of 10-400 nm and an average particle size of $72.74 \mathrm{~nm}$ were embedded in amorphous carbon, where WCNPs also dispersed. The particle size distribution of AgNPs existing in carbon-WC-Ag nanoparticles is shown in Figure S1c. The results of TEM are in good agreement with the results of XRD and Raman spectroscopy.
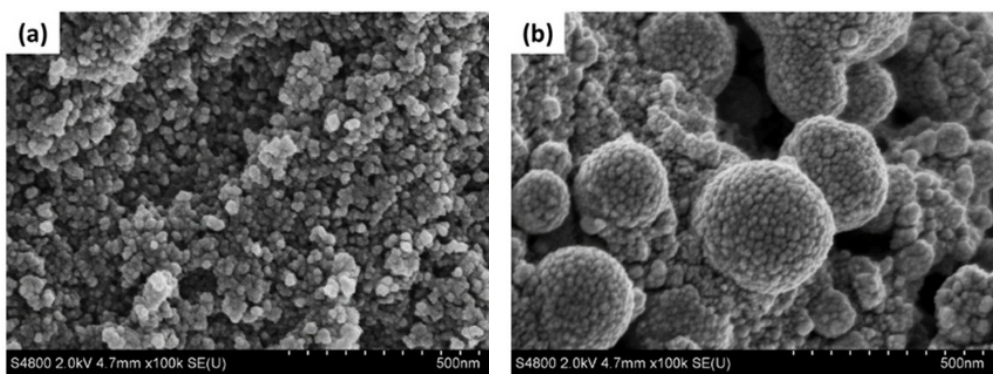

Figure 3. FE-SEM images of (a) carbon-WC and (b) carbon-WC-Ag nanoparticles at magnification of $100,000 \times$.
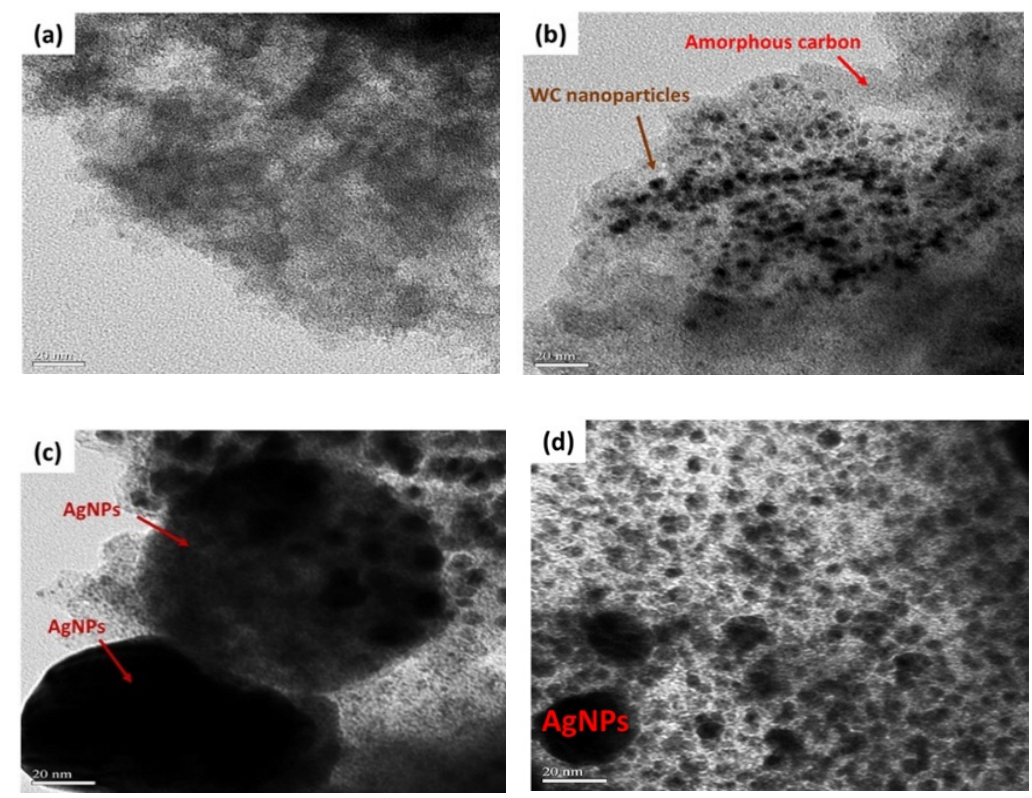

Figure 4. TEM images of (a) activated charcoal, (b) carbon-WC, (c,d) carbon-WC-Ag nanoparticles at magnification of $200,000 \times$. 
Furthermore, atomic percentages of each element in activated charcoal, carbon-WC, carbon-Ag and carbon-WC-Ag nanoparticles were investigated by scanning electron microscopy with energy dispersive X-ray (SEM-EDX) analysis and the results are shown in Table 2. The tungsten contents in carbon-WC and carbon-WC-Ag nanoparticles were 3.59\% and $3.81 \%$, respectively, whereas the silver contents in carbon-Ag and carbon-WC-Ag nanoparticles were $10.81 \%$ and $11.20 \%$, respectively.

Table 2. Elemental compositions of activated charcoal, carbon-WC, carbon-Ag and carbon-WC-Ag nanoparticles $(n=3)$.

\begin{tabular}{ccccc}
\hline \multirow{2}{*}{ Type of Elements } & \multicolumn{4}{c}{ Atomic Percentage (\%) \pm SD } \\
\cline { 2 - 5 } & Activated Charcoal & Carbon-WC & Carbon-Ag & Carbon-WC-Ag \\
\hline Carbon $(\mathrm{C})$ & $94.42 \pm 0.16$ & $91.15 \pm 0.46$ & $82.10 \pm 1.44$ & $75.35 \pm 2.04$ \\
Oxygen $(\mathrm{O})$ & $5.58 \pm 0.16$ & $5.35 \pm 0.72$ & $7.08 \pm 0.85$ & $9.64 \pm 1.60$ \\
Tungsten $(\mathrm{W})$ & - & $3.59 \pm 1.07$ & - & $3.81 \pm 0.83$ \\
Silver $(\mathrm{Ag})$ & - & - & $10.81 \pm 1.06$ & $11.20 \pm 1.18$ \\
\hline
\end{tabular}

\subsection{Morphology of Neat PLA and PLA Composite Films}

The SEM images of the surface morphology of neat PLA and PLA/carbon-WC-Ag composite films with different filler contents of $0.25,0.75,1.23,1.72$ and $2.20 \mathrm{wt} \%$ were taken (Figure S2). While the neat PLA film (Figure S2a) had a smooth surface, the PLA/carbonWC-Ag composite films (Figure S2b-f) had rugged surfaces due to the presence of carbonWC-Ag nanoparticles in the composite films. The SEM images of the composite films indicated that, at the filler contents of $0.25,0.75$ and $1.23 \mathrm{wt} \%$ (Figure S2b-d), carbon-WCAg nanoparticles had low aggregation and could maintain random dispersion in the PLA matrix. However, at the higher filler contents of 1.72 and $2.20 \mathrm{wt} \%$ (Figure S2e-f), the aggregation of carbon-WC-Ag nanoparticles in the PLA matrix was obviously observed. Accordingly, the PLA/carbon-WC-Ag composite films with the filler content of $1.23 \mathrm{wt} \%$ were used for further studies. In addition, an SEM image of the cross-sectional morphology of the PLA/carbon-WC-Ag composite film at the filler content of $1.23 \mathrm{wt} \%$ was taken (Figure S3). It is clearly shown that carbon-WC-Ag nanoparticles were embedded in the PLA matrix and the average film thickness was measured to be $95.5 \pm 0.52 \mu \mathrm{m}(n=3)$.

\subsection{Thermogravimetric Analysis}

TGA of neat PLA and PLA composite films, i.e., PLA/activated charcoal, PLA/carbonWC, PLA/carbon-Ag and PLA/carbon-WC-Ag, at the filler content of $1.23 \mathrm{wt} \%$, was performed and the values of the initial degradation temperature $\left(\mathrm{T}_{\text {int }}\right)$, the $50 \%$ weight loss temperature $\left(\mathrm{T}_{50}\right)$ and the degradation temperature $\left(\mathrm{T}_{\max }\right)$ are listed in Table 3 . According to the TGA results, the $\mathrm{T}_{\text {int }}$ of PLA/carbon-WC-Ag composite film was significantly higher than that of the neat PLA film, indicating the increment of thermal stability of the PLA/carbon-WC-Ag composite film at the initial state of thermal degradation. This might be due to the heat capacity of WCNPs and AgNPs, which could absorb heat during the initial state of thermal degradation. It is known that various types of transition metals and alkali earth metal oxides favor the thermal decomposition of PLA, leading to a reduction in the thermal stability of PLA [7,66-68]. Compared with the neat PLA film, a reduction in $\mathrm{T}_{50}$ and $\mathrm{T}_{\max }$ of PLA/carbon-WC composite films was observed. This result suggested that the presence of carbon-WC in the composite films could accelerate the thermal degradation of PLA. On the contrary, only a slight reduction in thermal stability of PLA/carbon-Ag composite film was observed when compared with the neat PLA film. Similarly, it has been reported that the presence of silver in the PLA matrix slightly affected the thermal stability of PLA composites [69,70]. 
Table 3. Initial degradation temperature $\left(T_{\text {int }}\right), 50 \%$ weight loss temperature $\left(T_{50}\right)$ and degradation temperature $\left(\mathrm{T}_{\max }\right)$ of neat PLA and PLA composite films at a filler content of $1.23 \mathrm{wt} \%$.

\begin{tabular}{cccc}
\hline Composite Films & $\mathbf{T}_{\text {int }}\left({ }^{\circ} \mathbf{C}\right)$ & $\mathbf{T}_{\mathbf{5 0}}\left({ }^{\circ} \mathbf{C}\right)$ & $\mathbf{T}_{\max }\left({ }^{\circ} \mathbf{C}\right)$ \\
\hline Neat PLA & $102.4^{\mathrm{a}}$ & $360.7^{\mathrm{a}}$ & $366.5^{\mathrm{a}}$ \\
PLA/activated charcoal & $104.9^{\mathrm{a}}$ & $358.9^{\mathrm{a}, \mathrm{b}}$ & $364.8^{\mathrm{a}, \mathrm{b}}$ \\
PLA/carbon-WC & $107.1^{\mathrm{a}}$ & $355.8^{\mathrm{a}}$ & $363.3^{\mathrm{a}}$ \\
PLA/carbon-Ag & $111.0^{\mathrm{a}}$ & $359.5^{\mathrm{a}, \mathrm{b}}$ & $365.7^{\mathrm{a}}$ \\
PLA/carbon-WC-Ag & $112.1^{\mathrm{a}}$ & $357.8^{\mathrm{a}}$ & $364.6^{\mathrm{a}, \mathrm{b}}$ \\
\hline
\end{tabular}

The superscript letter " $a$ " refers to significant differences among $\mathrm{T}_{\mathrm{int}}, \mathrm{T}_{50}$ and $\mathrm{T}_{\max }$ of the PLA composite films at $p$-value $<0.05$. The superscript letter " $\mathrm{b}$ " refers to non-significant difference between $\mathrm{T}_{50}$ of PLA/activated charcoal and PLA/carbon-Ag and non-significant difference between $\mathrm{T}_{\max }$ of PLA/activated charcoal and PLA/carbon-WC-Ag at $p$-value $<0.05$.

Considering the $\mathrm{T}_{50}$ and $\mathrm{T}_{\max }$ of PLA/carbon-WC-Ag composite films, the reduction in the thermal stability of PLA/carbon-WC-Ag composite films was less than that of PLA/carbon-WC composite films but higher than that of PLA/carbon-Ag composite films. As mentioned previously, carbon-WC could accelerate the thermal degradation of PLA, whereas AgNPs slightly affected the thermal stability of the composite films. It might be implied that the coexistence of AgNPs in carbon-WC-Ag could hinder the effect of WCNPs on the degradation of PLA upon heating. Nevertheless, the PLA/carbon-WC-Ag composite films had intrinsic thermal degradation properties. Therefore, the PLA/carbon-WC-Ag composite film is a potential candidate for use as an environmentally friendly material.

\subsection{Differential Scanning Calorimetry}

The effect of the incorporation of the fillers, i.e., activated carbon, carbon-WC, carbon$\mathrm{Ag}$ and carbon-WC-Ag nanoparticles, into PLA on the non-isothermal crystallization behavior of PLA was investigated by DSC via heating-cooling-heating scans and the results are shown in Figure 5. The glass transition temperature $\left(\mathrm{T}_{\mathrm{g}}\right)$, the cold crystallization temperature $\left(\mathrm{T}_{\mathrm{cc}}\right)$ and the melting temperature $\left(\mathrm{T}_{\mathrm{m}}\right)$ of neat PLA and the PLA composite films are detailed in Table 4. No significant change in the $T_{g}$ of all the PLA composite films was observed when compared with the neat PLA film, indicating that the presence of the synthesized carbon-based nanoparticles, i.e., carbon-WC, carbon-Ag and carbon-WC-Ag, in PLA matrix did not affect the mobility of PLA chains in amorphous regions $[39,71]$.

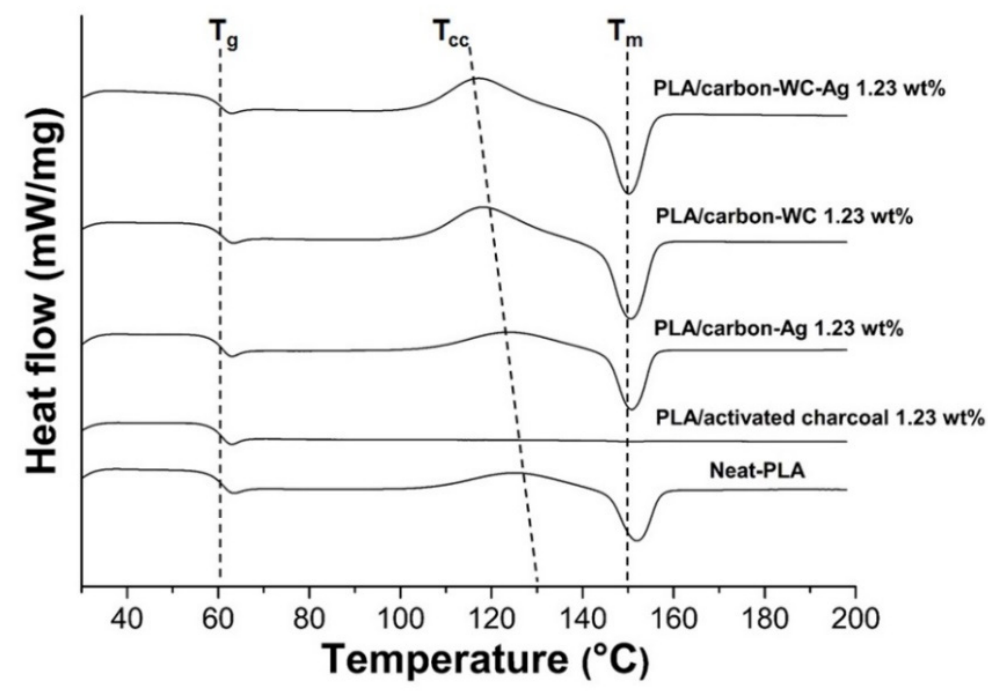

Figure 5. DSC thermograms of neat PLA and the PLA composite films at a filler content of $1.23 \mathrm{wt} \%$. 
Table 4. Glass transition temperature $\left(\mathrm{T}_{\mathrm{g}}\right)$, cold crystallization temperature $\left(\mathrm{T}_{\mathrm{cc}}\right)$ and melting temperature $\left(\mathrm{T}_{\mathrm{m}}\right)$ at the second heating scan of neat PLA and the PLA composite films at a filler content of $1.23 \mathrm{wt} \%$.

\begin{tabular}{cccc}
\hline Composite Films & $\mathbf{T}_{\mathbf{g}}\left({ }^{\circ} \mathbf{C}\right)$ & $\mathbf{T}_{\mathbf{c c}}\left({ }^{\circ} \mathbf{C}\right)$ & $\mathbf{T}_{\mathbf{m}}\left({ }^{\circ} \mathbf{C}\right)$ \\
\hline Neat PLA & $60.1^{\mathrm{b}}$ & $124.8^{\mathrm{a}}$ & $152.0^{\mathrm{a}}$ \\
PLA/activated charcoal & $59.6^{\mathrm{b}}$ & - & $150.7^{\mathrm{b}}$ \\
PLA/carbon-WC & $59.9^{\mathrm{b}}$ & $118.1^{\mathrm{a}}$ & $150.6^{\mathrm{b}}$ \\
PLA/carbon-Ag & $59.8^{\mathrm{b}}$ & $123.9^{\mathrm{a}}$ & $150.7^{\mathrm{b}}$ \\
PLA/carbon-WC-Ag & $59.3^{\mathrm{b}}$ & $117.1^{\mathrm{a}}$ & $150.1^{\mathrm{b}}$ \\
\hline
\end{tabular}

The superscript letter " $\mathrm{a}$ " refers to significant differences among $\mathrm{T}_{\mathrm{cc}}$ of the PLA composite films at $p$-value $<0.05$ The superscript letter " $\mathrm{b}$ " refers to non-significant differences among $\mathrm{T}_{\mathrm{g}}$ and $\mathrm{T}_{\mathrm{m}}$ of the PLA composite films at $p$-value $<0.05$.

On the other hand, it was found that the incorporation of carbon-WC, carbon-Ag and carbon-WC-Ag nanoparticles as fillers in the PLA composite films resulted in shifts in the $\mathrm{T}_{\mathrm{cc}}$ of the PLA composite films to lower temperatures compared with that of the neat PLA film, indicating the nucleating effect of the fillers. Due to the presence of polar functional groups such as carbonyl groups and high surface area, the synthesized carbonbased nanoparticles could interact with PLA and create nucleating sites to initiate the crystallization of PLA, resulting in an increase in the crystallization of PLA.

The presence of WCNPs and AgNPs in the synthesized carbon-based nanoparticles affected the nucleation ability of the synthesized carbon-based nanoparticles on the crystallization of PLA. It was found that the cold crystallization peak of PLA/carbon-WC was sharper and shifted to a lower temperature when compared to that of PLA/carbon-Ag (Figure 5). The lower $\mathrm{T}_{\mathrm{cc}}$ in the second heating scan indicated the faster crystallization of PLA, which was induced by the added carbon-WC [10]. It might be implied that the presence of WCNPs in the synthesized carbon-based nanoparticles could promote the interaction between the synthesized carbon-based nanoparticles and PLA chains and subsequently enhance the nucleation ability of the synthesized carbon-based nanoparticles to accelerate the crystallization process of PLA.

Moreover, the $\mathrm{T}_{\mathrm{cc}}$ of PLA/carbon-WC-Ag was lower than those of PLA/carbon-WC and PLA/carbon-Ag, suggesting the synergetic effect of the nucleation ability of WCNPs and AgNPs, accelerating the crystallization process of PLA. The $T_{m}$ of all the PLA composite films shifted to lower temperatures when compared with that of the neat PLA film. This might be due to the transformation of the crystalline structure of PLA to the imperfect crystal forms during cold crystallization and the imperfect crystal forms could re-melt at a lower temperature $[9,72]$.

\subsection{X-ray Diffraction}

Figure 6 shows XRD patterns of neat PLA and the PLA composite films, i.e., PLA/activated charcoal, PLA/carbon-Ag, PLA/carbon-WC and PLA/carbon-WC-Ag, at the filler content of $1.23 \%$ wt. The XRD pattern of the neat PLA film exhibited a diffraction peak at $2 \theta=16.64^{\circ}$, which corresponds to the (110)/ (200) planes of crystalline PLA [73]. It was found that the intensity of the diffraction peak at $2 \theta=16.64^{\circ}$ in the XRD pattern of PLA/carbon-WCAg was much higher than those of neat PLA, PLA/activated charcoal, PLA/carbon-Ag and PLA/carbon-WC. From XRD analysis, it was found that the values of the degree of crystallinity $\left(\chi_{c}\right)$ of neat PLA, PLA/activated charcoal, PLA/carbon-Ag, PLA/carbon-WC and PLA/carbon-WC-AgNPs were $1.43 \%, 1.52 \%, 2.20 \%, 5.94 \%$ and $14.23 \%$, respectively. This evidence confirmed that carbon-WC-Ag nanoparticles could lead to an improved crystalline structure of PLA by the co-nucleation ability of WCNPs and AgNPs coexisting in carbon-WC-Ag nanoparticles. 


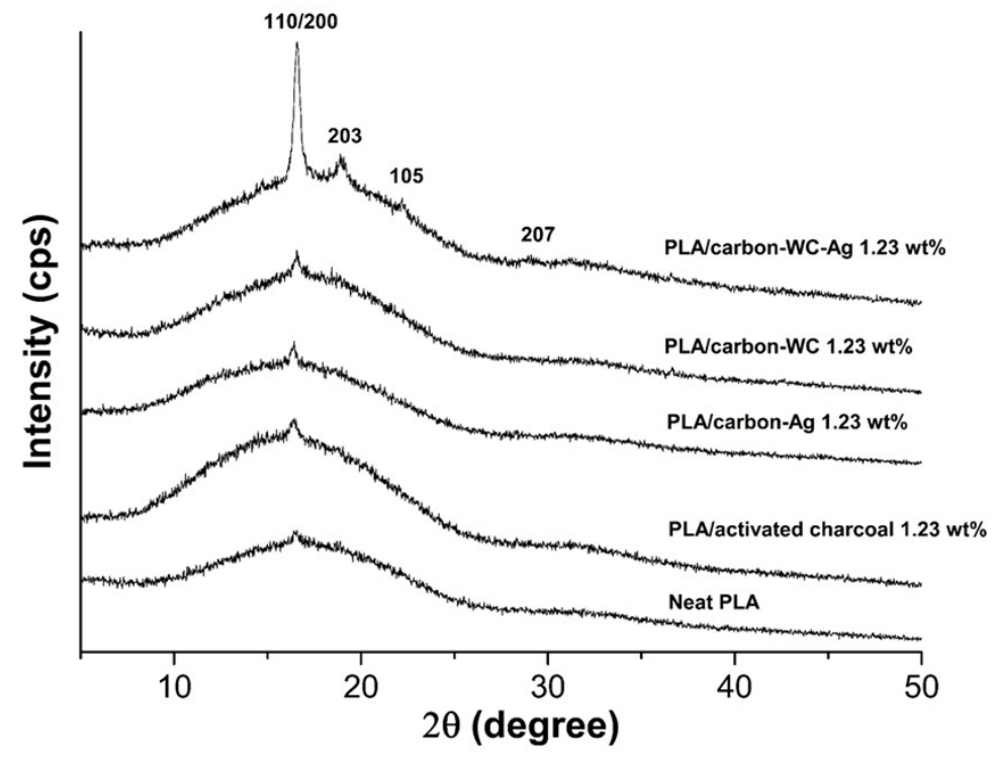

Figure 6. XRD patterns of neat PLA and the PLA composite films at a filler content of $1.23 \mathrm{wt} \%$.

\subsection{Mechanical Test}

In general, there are two possible factors that can influence the mechanical properties of PLA. The first is the dispersion of fillers in the PLA matrix and the second is the crystallinity of PLA, which depends largely on the crystallization behavior of PLA [39,74]. In this study, the Young's modulus of the neat PLA film was 6.45 GPA. At the filler content of $1.23 \mathrm{wt} \%$, the values of the Young's modulus of PLA/activated charcoal, PLA/carbonWC, PLA/carbon-Ag and PLA/carbon-WC-Ag composite films were 7.24, 7.74, 7.97 and 8.07 GPa, respectively. These results indicated that the presence of activated charcoal, carbon-WC, carbon-Ag and carbon-WC-Ag in the PLA matrix led to an increase in the Young's modulus of PLA. The increased Young's modulus was related to the DSC results showing that the co-nucleation of WCNPs and AgNPs coexisting in carbon-WC-Ag nanoparticles could accelerate the crystallization process of PLA, resulting in a better crystalline structure and higher Young's modulus of PLA/carbon-WC-Ag composite films.

The values of tensile strength of the neat PLA, PLA/activated charcoal, PLA/carbonWC, PLA/carbon-Ag and PLA/carbon-WC-Ag composite films were 19.92, 26.75, 21.16, 31.02 and $29.10 \mathrm{MPa}$, respectively. Due to the presence of some degree of aggregation of carbon-WC in the PLA matrix, the tensile strength of the PLA/carbon-WC composite film was not much higher than that of the neat PLA film. However, the incorporation of $1.23 \mathrm{wt} \%$ carbon-WC-Ag nanoparticles into the PLA matrix resulted in an increase in the tensile strength of PLA/carbon-WC-Ag composite films by $46.08 \%$ when compared with that of the neat PLA film. Since carbon-WC-Ag nanoparticles had bumpy surfaces, as evidenced by the SEM images, the surface roughness of carbon-WC-Ag nanoparticles might help to reduce the aggregation of carbon-WC-Ag nanoparticles in the PLA matrix, leading to a decrease in the stress concentrated point and consequently an increase in tensile strength [75]. Accordingly, it might be concluded that the incorporation of carbonWC-Ag nanoparticles as fillers in the PLA matrix, even at a low filler content of $1.23 \mathrm{wt} \%$, could significantly improve the Young's modulus and tensile strength of the resulting PLA/carbon-WC-Ag composite films.

\subsection{Antibacterial Test}

Antibacterial activities against E. coli and S. aureus of the neat PLA and the PLA composite films were evaluated by colony-forming unit assay. The cell suspensions without the addition of tested samples were used as controls. It was found that the neat PLA film had no antibacterial activity against E. coli and S. Aureus, whereas the presence of activated charcoal and carbon-WC in the PLA composite films resulted in negligible 
inhibitory effects on E. coli and S. Aureus. The bacterial reduction rate (BRR) of the PLA composite film containing $1.23 \mathrm{wt} \%$ of carbon-WC-Ag nanoparticles against $E$. coli and S. aureus was $61.22 \%$ and $52.17 \%$, respectively. It is well-known that AgNPs are used as a powerful antimicrobial agent. However, the deposition of AgNPs on a supporting material such as carbon may hinder the diffusion of AgNPs, resulting in lower antimicrobial activity than the corresponding unbound AgNPs. On the other hand, this may lead to better biocompatibility [22,76,77] when AgNPs deposited on a supporting material are incorporated into biomaterials for use in contact with living cells, such as in medical implants. Accordingly, the PLA/carbon-WC-Ag composites may be further developed for not only packaging materials but also biomedical applications.

\section{Conclusions}

Carbon-WC-Ag nanoparticles were simply synthesized in one step with the aid of SPP by using palm oil containing droplets of $\mathrm{AgNO}_{3}$ solution as carbon and silver precursors, respectively. Instead of using chemical agents, highly active species generated during plasma discharge induced the formation of carbon-WC-Ag nanoparticles. The synthesized carbon-WC-Ag nanoparticles were subsequently examined as multifunctional fillers for the preparation of PLA composite films fabricated by solution casting. The optimum content of carbon-WC-Ag nanoparticles in the PLA/carbon-WC-Ag composite film was $1.23 \mathrm{wt} \%$. Interestingly, WCNPs and AgNPs coexisting in carbon-WC-Ag nanoparticles exhibited a conucleation ability to accelerate the crystallization process of PLA, resulting in an enhanced crystalline structure of the PLA/carbon-WC-Ag composite films. It was found that the degree of crystallinity of PLA/carbon-WC-Ag composite films was roughly ten times higher than that of neat PLA film. Consequently, the Young's modulus and tensile strength of the PLA/carbon-WC-Ag composite films could be significantly improved. Moreover, WCNPs in the PLA composite films might be involved in the enhancement of the thermal degradation of PLA, leading to an advantage in their degradation. Due to the presence of AgNPs, the PLA/carbon-WC-Ag composite films exhibited antibacterial activities against E. coli and S. aureus. The evidence in this study indicates that SPP is a powerful tool for the synthesis of multicomponent nanoparticles. Moreover, multicomponent nanoparticles such as carbon-WC-Ag nanoparticles are useful as multifunctional fillers for the development of PLA composites aimed at packaging and biomaterial applications.

Supplementary Materials: The following are available online at https:/ / www.mdpi.com/2073-4 360/13/7/991/s1, Figure S1: Particle size distribution of (a) carbon-WC nanoparticles from SEM images, (b) carbon-WC-Ag nanoparticles from SEM images and (c) AgNPs existing in carbon-WCAg nanoparticles from TEM images $(\mathrm{n}=300)$, Figure S2: SEM images of surface morphology of (a) neat PLA film and PLA/carbon-WC-Ag composite films with different filler contents of (b) 0.25 , (c) 0.75, (d) 1.23, (e) 1.72 and (f) $2.20 \mathrm{wt} \%$, Figure S3: FE-SEM image of cross-sectional morphology of PLA/carbon-WC-Ag composite films at the filler content of $1.23 \mathrm{wt} \%$ (magnification of $1000 \times$ ).

Author Contributions: Conceptualization, R.R.; investigation, N.B.; resources, N.S.; writingoriginal draft preparation, N.B.; writing-review and editing, R.R.; supervision, R.R.; funding acquisition, R.R. All authors have read and agreed to the published version of the manuscript.

Funding: The authors would like to acknowledge the support from the Thai Government Budget Grant under the grant number 255245, Ratchadapisek Sompot Endowment Fund from Chulalongkorn University under the grant number GCUGR1125613107D and JST/CREST under the grant number GJPMJCR12L1. This work was also partially supported by the JSPS Core-to-Core Program, B. AsiaAfrica Science Platforms and Chulalongkorn University by Office of International Affairs Scholarship for Short-Term Research.

Institutional Review Board Statement: Not applicable.

Informed Consent Statement: Not applicable.

Data Availability Statement: The data presented in this study are available on request from the corresponding author. 
Acknowledgments: N.B. would like to thank the Center of Excellence on Petrochemical and Materials Technology (PETROMAT) for providing her with a Ph.D. Scholarship under the grant number 01-0401-001327.

Conflicts of Interest: The authors declare no conflict of interest.

\section{References}

1. Fazita, M.R.N.; Jayaraman, K.; Bhattacharyya, D.; Hossain, M.S.; Haafiz, M.K.M.; Khalil, A. Disposal options of bamboo fabricreinforced poly(Lactic) acid composites for sustainable packaging: Biodegradability and recyclability. Polymers 2015, 7, 1476-1496. [CrossRef]

2. Guo, Y.; Wang, L.; Chen, Y.; Luo, P.; Chen, T. properties of luffa fiber reinforced PHBV biodegradable composites. Polymers 2019, 11, 1765. [CrossRef] [PubMed]

3. Huh, M.; Jung, M.; Park, Y.; Kim, B.-J.; Kang, M.; Holden, P.; Yun, S. Effect of carbon nanotube functionalization on the structure and properties of poly(3-hydroxybutyrate)/MWCNTs biocomposites. Macromol. Res. 2014, 22, 765. [CrossRef]

4. Li, T.; Sun, H.; Wu, B.; Han, H.; Li, D.; Wang, J.-K.; Zhang, J.; Huang, J.; Sun, D. High-performance polylactic acid composites reinforced by artificially cultured diatom frustules. Mater. Des. 2020, 195, 109003. [CrossRef]

5. Le Phuong, H.A.; Izzati Ayob, N.A.; Blanford, C.F.; Mohammad Rawi, N.F.; Szekely, G. Nonwoven membrane supports from renewable resources: Bamboo fiber reinforced poly(Lactic Acid) composites. ACS Sustain. Chem. Eng. 2019, 7, 11885-11893. [CrossRef]

6. $\mathrm{Xu}, \mathrm{A} . ;$ Wang, Y.; Gao, J.; Wang, J. Facile fabrication of a homogeneous cellulose/polylactic acid composite film with improved biocompatibility, biodegradability and mechanical properties. Green Chem. 2019, 21, 4449-4456. [CrossRef]

7. Gorrasi, G.; Milone, C.; Piperopoulos, E.; Lanza, M.; Sorrentino, A. Hybrid clay mineral-carbon nanotube-PLA nanocomposite films. Preparation and photodegradation effect on their mechanical, thermal and electrical properties. Appl. Clay Sci. 2013, 71, 49-54. [CrossRef]

8. Khan, B.A.; Chevali, V.S.; Na, H.; Zhu, J.; Warner, P.; Wang, H. Processing and properties of antibacterial silver nanoparticle-loaded hemp hurd/poly(lactic acid) biocomposites. Compos. B Eng. 2016, 100, 10-18. [CrossRef]

9. Chen, P.; Zhou, H.; Liu, W.; Zhang, M.; Du, Z.; Wang, X. The synergistic effect of zinc oxide and phenylphosphonic acid zinc salt on the crystallization behavior of poly (lactic acid). Polym. Degrad. Stab. 2015, 122, 25-35. [CrossRef]

10. Naffakh, M.; Marco, C.; Ellis, G. Non-isothermal cold-crystallization behavior and kinetics of poly(l-lactic Acid)/WS 2 inorganic nanotube nanocomposites. Polymers 2015, 7, 2175-2189. [CrossRef]

11. Wang, N.; Zhang, X.; Ma, X.; Fang, J. Influence of carbon black on the properties of plasticized poly(lactic acid) composites. Polym. Degrad. Stab. 2008, 93, 1044-1052. [CrossRef]

12. Zhou, Y.; Lei, L.; Yang, B.; Li, J.; Ren, J. Preparation and characterization of polylactic acid (PLA) carbon nanotube nanocomposites. Polym. Test 2018, 68, 34-38. [CrossRef]

13. Pan, W.; Xiao, X.; Li, J.; Deng, S.; Shan, Q.; Yue, Y.; Tian, Y.; Nabar, N.R.; Wang, M.; Hao, L. The comparison of biocompatibility and osteoinductivity between multi-walled and single-walled carbon nanotube/PHBV composites. J. Mater. Sci. Mater. Med. 2018, 29, 189. [CrossRef]

14. Yang, S.; Wang, S.; Liu, X.; Li, L. Biomass derived interconnected hierarchical micro-meso-macro- porous carbon with ultrahigh capacitance for supercapacitors. Carbon 2019, 147, 540-549. [CrossRef]

15. Pontiroli, D.; Scaravonati, S.; Magnani, G.; Fornasini, L.; Bersani, D.; Bertoni, G.; Milanese, C.; Girella, A.; Ridi, F.; Verucchi, R.; et al. Super-activated biochar from poultry litter for high-performance supercapacitors. Microporous Mesoporous Mater. 2019, 285, 161-169. [CrossRef]

16. Aup-Ngoen, K.; Noipitak, M. Effect of carbon-rich biochar on mechanical properties of PLA-biochar composites. Sustain. Chem. Pharm. 2020, 15, 100204. [CrossRef]

17. Takagi, H.; Kako, S.; Kusano, K.; Ousaka, A. Thermal conductivity of PLA-bamboo fiber composites. Adv. Compos. Mater. 2007, 16, 377-384. [CrossRef]

18. Yu, H.; Sun, B.; Zhang, D.; Chen, G.; Yang, X.; Yao, J. Reinforcement of biodegradable poly(3-hydroxybutyrate-co-3hydroxyvalerate) with cellulose nanocrystal/silver nanohybrids as bifunctional nanofillers. J. Mater. Chem. B 2014, 2, 8479-8489. [CrossRef]

19. Bai, T.; Zhu, B.; Liu, H.; Wang, Y.; Song, G.; Liu, C.; Shen, C. Biodegradable poly(lactic acid) nanocomposites reinforced and toughened by carbon nanotubes/clay hybrids. Int. J. Biol. Macromol. 2020, 151, 628-634. [CrossRef]

20. Fortunati, E.; Armentano, I.; Zhou, Q.; Iannoni, A.; Saino, E.; Visai, L.; Berglund, L.A.; Kenny, J.M. Multifunctional bionanocomposite films of poly(lactic acid), cellulose nanocrystals and silver nanoparticles. Carbohydr. Polym. 2012, 87, 1596-1605. [CrossRef]

21. Yu, H.-Y.; Yang, X.-Y.; Lu, F.-F.; Chen, G.-Y.; Yao, J.-M. Fabrication of multifunctional cellulose nanocrystals/poly(lactic acid) nanocomposites with silver nanoparticles by spraying method. Carbohydr. Polym. 2016, 140, 209-219. [CrossRef]

22. Tsou, C.H.; Yao, W.H.; Lu, Y.C.; Tsou, C.Y.; Wu, C.S.; Chen, J.; Wang, R.Y.; Su, C.; Hung, W.S.; De Guzman, M.; et al. Antibacterial property and cytotoxicity of a poly(lactic acid)/nanosilver-doped multiwall carbon nanotube nanocomposite. Polymers 2017, 9, 100. [CrossRef] [PubMed]

23. Zhang, H.; Yu, H.-Y.; Wang, C.; Yao, J. Effect of silver contents in cellulose nanocrystal/silver nanohybrids on PHBV crystallization and property improvements. Carbohydr. Polym. 2017, 173, 7-16. [CrossRef] 
24. Kang, J.; Li, O.L.; Saito, N. Synthesis of structure-controlled carbon nano spheres by solution plasma process. Carbon 2013, 60, 292-298. [CrossRef]

25. Matsuda, N.; Nakashima, T.; Kato, T.; Shiroishi, H. Synthesis of multiwall carbon nanotube-supported platinum catalysts by solution plasma processing for oxygen reduction in polymer electrolyte fuel cells. Electrochim. Acta 2014, 146, 73-78. [CrossRef]

26. Panomsuwan, G.; Saito, N.; Ishizaki, T. Nitrogen-doped carbon nanoparticles derived from acrylonitrile plasma for electrochemical oxygen reduction. Phys. Chem. Chem. Phys. 2015, 17, 6227-6232. [CrossRef]

27. Nemoto, S.; Ueno, T.; Hieda, J.; Bratescu, M.A.; Saito, N.; Watthanaphanit, A. Simple introduction of carboxyl head group with alkyl spacer onto multiwalled carbon nanotubes by solution plasma process. Jpn. J. Appl. Phys. 2017, 56, 096202. [CrossRef]

28. Saito, N.; Hieda, J.; Takai, O. Synthesis process of gold nanoparticles in solution plasma. Thin Solid Films 2009, 518, 912-917. [CrossRef]

29. Tong, D.G.; Wu, P.; Su, P.K.; Wang, D.Q.; Tian, H.Y. Preparation of zinc oxide nanospheres by solution plasma process and their optical property, photocatalytic and antibacterial activities. Mater. Lett. 2012, 70, 94-97. [CrossRef]

30. Kang, J.; Li, O.L.; Saito, N. A simple synthesis method for nano-metal catalyst supported on mesoporous carbon: The solution plasma process. Nanoscale 2013, 5, 6874-6882. [CrossRef]

31. Panomsuwan, G.; Chantaramethakul, J.; Chokradjaroen, C.; Ishizaki, T. In situ solution plasma synthesis of silver nanoparticles supported on nitrogen-doped carbons with enhanced oxygen reduction activity. Mater. Lett. 2019, 251, 135-139. [CrossRef]

32. Panomsuwan, G.; Saito, N.; Ishizaki, T. Fe-N-doped carbon-based composite as an efficient and durable electrocatalyst for the oxygen reduction reaction. RSC Adv. 2016, 6, 114553-114559. [CrossRef]

33. Kim, D.-w.; Li, O.L.; Pootawang, P.; Saito, N. Solution plasma synthesis process of tungsten carbide on N-doped carbon nanocomposite with enhanced catalytic ORR activity and durability. RSC Adv. 2014, 4, 16813-16819. [CrossRef]

34. Takai, O. Solution plasma processing (SPP). Pure Appl. Chem. 2008, 80, 2003-2011. [CrossRef]

35. Prasertsung, I.; Damrongsakkul, S.; Saito, N. Degradation of $\beta$-chitosan by solution plasma process (SPP). Polym. Degrad. Stab. 2013, 98, 2089-2093. [CrossRef]

36. Morishita, T.; Ueno, T.; Panomsuwan, G.; Hieda, J.; Yoshida, A.; Bratescu, M.A.; Saito, N. Fastest formation routes of nanocarbons in solution plasma processes. Sci. Rep. 2016, 6, 36880. [CrossRef]

37. Salifairus, M.J.; Abd Hamid, S.B.; Soga, T.; Alrokayan, S.A.; Khan, H.A.; Rusop, M. Structural and optical properties of graphene from green carbon source via thermal chemical vapor deposition. J. Mater. Res. 2016, 31, 1947-1956. [CrossRef]

38. Ishak, A.; Dayana, K.; Mamat, M.H.; Malek, M.F.; Rusop, M. Nano-structured amorphous carbon films using novel palm oil precursor for solar cell applications. Optik 2015, 126, 1610-1612. [CrossRef]

39. Fonseca, C.; Ochoa, A.; Ulloa, M.T.; Alvarez, E.; Canales, D.; Zapata, P.A. Poly(lactic acid)/ $\mathrm{TiO}_{2}$ nanocomposites as alternative biocidal and antifungal materials. Mater. Sci. Eng. C 2015, 57, 314-320. [CrossRef]

40. Villani, M.; Consonni, R.; Canetti, M.; Bertoglio, F.; Iervese, S.; Bruni, G.; Visai, L.; Iannace, S.; Bertini, F. Polyurethane-Based Composites: Effects of Antibacterial Fillers on the Physical-Mechanical Behavior of Thermoplastic Polyurethanes. Polymers 2020, 12, 362. [CrossRef]

41. Marra, A.; Silvestre, C.; Duraccio, D.; Cimmino, S. Polylactic acid/zinc oxide biocomposite films for food packaging application. Int. J. Biol. Macromol. 2016, 88, 254-262. [CrossRef]

42. Alammar, A.; Park, S.-H.; Williams, C.J.; Derby, B.; Szekely, G. Oil-in-water separation with graphene-based nanocomposite membranes for produced water treatment. J. Membr. Sci. 2020, 603, 118007. [CrossRef]

43. Rubin, H.N.; Neufeld, B.H.; Reynolds, M.M. Surface-Anchored Metal-Organic Framework-Cotton Material for Tunable Antibacterial Copper Delivery. ACS Appl. Mater. Interfaces 2018, 10, 15189-15199. [CrossRef]

44. Al Aani, S.; Gomez, V.; Wright, C.J.; Hilal, N. Fabrication of antibacterial mixed matrix nanocomposite membranes using hybrid nanostructure of silver coated multi-walled carbon nanotubes. Chem. Eng. J. 2017, 326, 721-736. [CrossRef]

45. Chen, D.; Qiao, X.; Qiu, X.; Chen, J. Synthesis and electrical properties of uniform silver nanoparticles for electronic applications. J. Mater. Sci. 2009, 44, 1076-1081. [CrossRef]

46. Zakaria, M.A.; Menazea, A.A.; Mostafa, A.M.; Al-Ashkar, E.A. Ultra-thin silver nanoparticles film prepared via pulsed laser deposition: Synthesis, characterization, and its catalytic activity on reduction of 4-nitrophenol. Surf. Interfaces 2020, $19,100438$. [CrossRef]

47. Boca, S.C.; Potara, M.; Gabudean, A.M.; Juhem, A.; Baldeck, P.L.; Astilean, S. Chitosan-coated triangular silver nanoparticles as a novel class of biocompatible, highly effective photothermal transducers for in vitro cancer cell therapy. Cancer Lett. 2011, 311, 131-140. [CrossRef]

48. Abdel-Halim, E.S.; Al-Deyab, S.S. Antimicrobial activity of silver/starch/polyacrylamide nanocomposite. Int. J. Biol. Macromol. 2014, 68, 33-38. [CrossRef] [PubMed]

49. Cañamares, M.V.; Garcia-Ramos, J.V.; Gómez-Varga, J.D.; Domingo, C.; Sanchez-Cortes, S. Comparative study of the morphology, aggregation, adherence to glass, and surface-enhanced Raman scattering activity of silver nanoparticles prepared by chemical reduction of Ag+ using citrate and hydroxylamine. Langmuir 2005, 21, 8546-8553. [CrossRef] [PubMed]

50. Li, Z.; Fan, L.; Zhang, T.; Li, K. Facile synthesis of Ag nanoparticles supported on MWCNTs with favorable stability and their bactericidal properties. J. Hazard. Mater. 2011, 187, 466-472. [CrossRef] [PubMed]

51. Kumar, R.; Munstedt, H. Silver ion release from antimicrobial polyamide/silver composites. Biomaterials 2005, 26, 2081-2088. [CrossRef] [PubMed] 
52. Lin, Y.; Qiao, Y.; Wang, Y.; Yan, Y.; Huang, J. Self-assembled laminated nanoribbon-directed synthesis of noble metallic nanoparticle-decorated silica nanotubes and their catalytic applications. J. Mater. Chem. 2012, 22, 18314-18320. [CrossRef]

53. Bhaduri, B.; Polubesova, T. Facile synthesis of carbon-supported silver nanoparticles as an efficient reduction catalyst for aqueous 2-methyl-p-nitrophenol. Mater. Lett. 2020, 267, 127546. [CrossRef]

54. Vijayakumar, P.S.; Prasad, B.L. Intracellular biogenic silver nanoparticles for the generation of carbon supported antiviral and sustained bactericidal agents. Langmuir 2009, 25, 11741-11747. [CrossRef] [PubMed]

55. Sudhakar, P.; Soni, H. Catalytic reduction of nitrophenols using silver nanoparticles-supported activated carbon derived from agro-waste. J. Environ. Chem. Eng. 2018, 6, 28-36. [CrossRef]

56. Surudžić, R.; Janković, A.; Bibić, N.; Vukašinović-Sekulić, M.; Perić-Grujić, A.; Mišković-Stanković, V.; Park, S.J.; Rhee, K.Y. Physico-chemical and mechanical properties and antibacterial activity of silver/poly(vinyl alcohol)/graphene nanocomposites obtained by electrochemical method. Compos. B Eng. 2016, 85, 102-112. [CrossRef]

57. Gan, L.; Geng, A.; Wu, Y.; Wang, L.; Fang, X.; Xu, L.; Mei, C. Antibacterial, flexible, and conductive membrane based on MWCNTs / Ag coated electro-Spun PLA nanofibrous scaffolds as wearable fabric for body motion sensing. Polymers 2020, 12, 120 [CrossRef]

58. Cheng, Y.; Li, H.; Fang, C.; Ai, L.; Chen, J.; Su, J.; Zhang, Q.; Fu, Q. Facile synthesis of reduced graphene oxide/silver nanoparticles composites and their application for detecting heavy metal ions. J. Alloy. Compd. 2019, 787, 683-693. [CrossRef]

59. Tammeveski, L.; Erikson, H.; Sarapuu, A.; Kozlova, J.; Ritslaid, P.; Sammelselg, V.; Tammeveski, K. Electrocatalytic oxygen reduction on silver nanoparticle/multi-walled carbon nanotube modified glassy carbon electrodes in alkaline solution. Electrochem. Commun. 2012, 20, 15-18. [CrossRef]

60. Ahmed, J.; Arfat, Y.A.; Castro-Aguirre, E.; Auras, R. Thermal properties of ZnO and bimetallic Ag-Cu alloy reinforced poly(lactic acid) nanocomposite films. J. Therm. Anal. Calorim. 2016, 125, 205-214. [CrossRef]

61. Abdul Rahaman, M.H.; Khandaker, M.U.; Khan, Z.R.; Kufian, M.Z.; Noor, I.S.M.; Arof, A.K. Effect of gamma irradiation on poly(vinyledene difluoride)-lithium bis(oxalato)borate electrolyte. Phys. Chem. Chem. Phys. 2014, 16, 11527-11537. [CrossRef] [PubMed]

62. Janpetch, N.; Saito, N.; Rujiravanit, R. Fabrication of bacterial cellulose-ZnO composite via solution plasma process for antibacterial applications. Carbohydr. Polym. 2016, 148, 335-344. [CrossRef] [PubMed]

63. Tanaka, S.; Bataev, I.; Oda, H.; Hokamoto, K. Synthesis of metastable cubic tungsten carbides by electrical explosion of tungsten wire in liquid paraffin. Adv. Powder Technol. 2018, 29, 2447-2455. [CrossRef]

64. Liu, C.; Zhou, D.; Zhou, J.; Xie, Z.; Xia, Y. Synthesis and characterization of tungsten carbide and application to electrocatalytic hydrogen evolution. RSC Adv. 2016, 6, 76307-76311. [CrossRef]

65. Kim, H.; Saito, N. One-pot synthesis of purple benzene-derived $\mathrm{MnO}_{2}$-carbon hybrids and synergistic enhancement for the removal of cationic dyes. Sci. Rep. 2018, 8, 4342. [CrossRef]

66. Cam, D.; Marucci, M. Influence of residual monomers and metals on poly (1-lactide) thermal stability. Polymer 1997, 38, 1879-1884. [CrossRef]

67. Fan, Y.; Nishida, H.; Mori, T.; Shirai, Y.; Endo, T. Thermal degradation of poly(l-lactide): Effect of alkali earth metal oxides for selective 1,l-lactide formation. Polymer 2004, 45, 1197-1205. [CrossRef]

68. Vijayalakshmi, S.P.; Madras, G. Thermal degradation of water soluble polymers and their binary blends. J. Appl. Polym. Sci. 2006, 101, 233-240. [CrossRef]

69. Doganay, D.; Coskun, S.; Kaynak, C.; Unalan, H.E. Electrical, mechanical and thermal properties of aligned silver nanowire/polylactide nanocomposite films. Compos. B Eng. 2016, 99, 288-296. [CrossRef]

70. Ramos, M.; Fortunati, E.; Peltzer, M.; Dominici, F.; Jiménez, A.; del Carmen Garrigós, M.; Kenny, J.M. Influence of thymol and silver nanoparticles on the degradation of poly(lactic acid) based nanocomposites: Thermal and morphological properties. Polym. Degrad. Stab. 2014, 108, 158-165. [CrossRef]

71. Piekarska, K.; Sowinski, P.; Piorkowska, E.; Haque, M.M.U.; Pracella, M. Structure and properties of hybrid PLA nanocomposites with inorganic nanofillers and cellulose fibers. Compos. Part A Appl. Sci. Manuf. 2016, 82, 34-41. [CrossRef]

72. Wang, L.; Wang, Y.-n.; Huang, Z.-g.; Weng, Y.-x. Heat resistance, crystallization behavior, and mechanical properties of polylactide/nucleating agent composites. Mater. Des. (1980-2015) 2015, 66, 7-15. [CrossRef]

73. Dai, X.; Cao, Y.; Shi, X.; Wang, X. Non-isothermal crystallization kinetics, thermal degradation behavior and mechanical properties of poly(lactic acid)/MOF composites prepared by melt-blending methods. RSC Adv. 2016, 6, 71461-71471. [CrossRef]

74. Liu, S.-Q.; Wu, G.-H.; Xiao, Y.-C.; Guo, H.-X.; Shao, F.-J. Crystallization behavior and mechanical properties of poly(lactic acid) complex fiber toughened by carbon nanotube nanocapsules. Text. Res. J. 2017, 88, 1616-1627. [CrossRef]

75. Mat Desa, M.S.Z.; Hassan, A.; Arsad, A.; Mohammad, N.N.B. Mechanical properties of poly(lactic acid)/multiwalled carbon nanotubes nanocomposites. Mater. Res. Innov. 2014, 18 (Suppl. 6), S6-14-S6-17. [CrossRef]

76. Castle, A.B.; Gracia-Espino, E.; Nieto-Delgado, C.; Terrones, H.; Terrones, M.; Hussain, S. Hydroxyl-functionalized and N-Doped multiwalled carbon nanotubes decorated with silver nanoparticles preserve cellular function. ACS Nano 2011, 5, $2458-2466$. [CrossRef] [PubMed]

77. Seo, Y.; Hwang, J.; Kim, J.; Jeong, Y.; Hwang, M.P.; Choi, J. Antibacterial activity and cytotoxicity of multi-walled carbon nanotubes decorated with silver nanoparticles. Int. J. Nanomed. 2014, 9, 4621-4629. 